\title{
QUALITATIVE INVESTIGATION OF COACHES' PERSPECTIVES ON MORAL EDUCATION IN SPORT
}

\author{
Saulius Šukys, Živilė Dargenė, Diana Karanauskienė \\ Lithuanian Sports University, Kaunas, Lithuania
}

\begin{abstract}
Background. Moral behaviour and moral education of young athletes still remain an important issue in sports context. This study was designed to examine coaches' perspectives on moral education in sport.

Methods. In this study, aiming at establishing the perspectives of coaches on the moral education of athletes in sports activities, qualitative research was selected. Primary data were collected via semi-structured interviews with nine basketball and football coaches of different experience and age. The data were analysed applying thematic analysis.

Results. Thematic analysis indicated that coaches identified goals of athletes' education as the development of athletes' personality, motivation, the development of sports excellence and the encouragement to achieve victory. Coaches defined moral education as the development of the authority of an athlete, fair play, compliance with rules, and integrity. The most common means coaches used for moral education were explanation, discussion, lectures, meetings, personal examples, case analyses. Such means are important for athlete's personal development, pursuit of results, and career planning. The qualities of good coach were professional knowledge, authority, competences of creating motivational climate, and also moral competences.

Conclusion. A central finding of the study is that coaches define moral education in sport through the education of moral values and the goals set by coaches related not only to the sports results, but also to the development of the personality of athletes. Personal role of coaches in moral education encompassing professional knowledge and moral competences of athletes is of great importance.
\end{abstract}

Keywords: morality in sport, moral values, coaches' role, athletes' education.

\section{INTRODUCTION}

$\Lambda$ number of scholars emphasize that sports activities are one of the most influencing and significant factors playing an important role in the development of personality traits, value orientations (Moreno \& Cervello, 2005; Popescu, 2012), positive youth development (Holt et al., 2017). Thus, the close relationship between sport activities and moral education is quite reasonable (Hardman, Jones, \& Jones, 2010). Moral education of athletes is important not only for internalization of moral values and models of moral conduct. Recent findings indicate that athletes' moral behaviour also positively relate to their effort, perceived performance, and enjoyment (Al-Yaaribi,
Kavussanu, \& Ring, 2016). However, the moral values grounding athletes' education basically depend on the coach (Pelaez, Aulls, \& Bacon, 2016). Besides, athletes also tend to embrace the values and behaviours that are provided by the coach (BergmannDrewe, 1999). Thus, the moral education of athletes depends on the favourable athletic environment developed by the coach and their relationships with athletes, which is special in that they can, to a certain extent, replace relationships with parents (Holt \& Knight, 2014).

It should be noted that issues of athletes' moral behaviour and its determining factors related to coach's behaviour have been widely researched. 
The investigation of coach character-building effectiveness and competency showed that rugby players who perceived that their coach was effective and competent in instilling an attitude of good moral character, fair play, and respect for others, and in promoting good sportspersonship, were more likely to report prosocial behaviour (Boardley \& Kavussanu, 2009; Boardley, Kavussanu, \& Ring, 2008). The analysis of coaches' fair play attitudes revealed that adolescent soccer players who perceived their coach as having fair play attitudes were less likely to engage in antisocial behaviour while playing soccer (Rutten et al., 2008).

A number of studies investigated motivational climate and athletes' moral behaviour. Results of these studies suggest that performance climate is related to adolescent athletes' antisocial behaviour (Bortoli, Messina, Zorba, \& Robazza, 2012; Sánchez-Miguel, Amado, \& García-Calvo, 2012) and perceived mastery climate is associated with athletes' sportspersonship (Ntoumanis, Taylor, \& Thøgersen-Ntoumani, 2012). Boardley and Kavussanu (2009) also indicated that coaches created a task-involving climate, which was associated with prosocial behaviour. A coach can structure the sports environment to be either autonomy supportive or controlling. As autonomy motivation has been shown to be positively associated with moral behaviour (Winstein \& Ryan, 2010), studies in sport found that autonomysupportive coaching style related to prosocial behaviour of athletes (Hodge \& Lonsdale, 2011).

Prevailing studies exploring the moral behaviour of athletes are quantitative. It is worth mentioning only a few qualitative studies that explain the moral disengagement mechanisms athletes use when they engage in antisocial behaviours in soccer (Traclet, Romand, Moret, \& Kavussanu, 2011). Bruner and colleagues (2016), applying stimulated recall interview, explored the importance of prosocial intra-team behaviour to their social identity in sport.

The morality and moral education from coaches' perspectives have not been widely investigated. Romand and Pantaleon (2007) analysed rugby coaches' attitudes toward the values they tried to teach their players, means they used to teach game rules, and prosocial norms. The data obtained during the interview revealed the complexity of the coach's role during the training sessions and the controversy between what they say and do. Rudd and Mondello's (2006) study examined how 12 head coaches of individual and team sports defined character. Findings from this study showed that most coaches defined character with a combination of moral and social values. On the other hand, the definitions given by coaches were too general, lacking specificity. Another study by Pelaez, Aulls and Bacon (2016) examined the perspectives on morality in sport of coaches of different gender, level of competition and sports. It was found that the coach perceived morality in two ways: from the moral perspective (distinction between right and wrong, doing what is right) and from the social perspective which dealt with issues that enhanced and facilitated sport involvement and pertained to the domain of team dynamics. The aforementioned studies revealed that coaches struggled to define morality in sport, and it was easier for them to describe not their own moral behaviour but that of others. It should be noted that previous studies did not deal much with the perspectives of coaches about moral education in the context of athletes' goals. Coaches also value the benefits of moral education in sport for athletes themselves. So the complexity of defining morality encourages further research by exploring coaches' perspectives on moral education in sport. Taken together, most previous studies revealed links between coaching characteristics and moral behaviour of athletes. In order to increase our understanding of moral education in sport and to address the limitation of previous questionnairebased studies (e.g., not capturing the perception of moral education itself), and few qualitative studies, in this study we used qualitative methodology to examine coaches' perspectives on moral education in sport.

\section{METHODS}

Study overview. In this study, aiming at establishing the perspectives of coaches on the moral education of athletes in sports activities, qualitative research was selected. Semi-structured interviews were applied to coaches of various experience and age.

Participants. Purposeful sampling was applied to select coaches of team sports for the study. One woman and eight men aged between 22 and 50 participated in the research $(M=33.4)$. The coaches' work experience was from 4 to 17 years $(M=7.6)$. Two coaches were training professional basketball teams participating in the highest national leagues, one coach was training a basketball team of adult 
men, another one - adolescent football team, four informants were working with pre-school (4-6 years) and school (7-18 years old) basketball teams, and another one was working with both children and adult basketball teams. Eight coaches had higher education, and one was studying in the last year at university.

Data collection. Semi-structured interviews were used to collect the study data. The choice of the method of semi-structured interviewing was determined by its immediacy, flexibility, the ability to collect data from a small group of informants, use of wider research questions and reveal social reality from the point of view of the research participants. As Sparkes and Smith (2014) suggest, "Although researchers do not ask the questions in the same way or form to each participant, the relatively tight structure allows them to collect the important information about the topic of interest while giving the participants the opportunity to report on their own thoughts and feelings" ( $\mathrm{p}$. $84)$. Thus, the chosen research method has the following advantages: it gives more freedom to the research participants than a structured interview; it provides the respondents with a certain degree of flexibility in expressing their thoughts, feelings and opinions; the informant can reveal more of the meanings associated with his or her experiences and thus allow the investigator to get to know them more deeply than this could be achieved through a structured interview (Sparkes \& Smith, 2014). Preliminary interview questions for the respondents were prepared, first of all asking the respondents to tell about themselves aiming at collecting socio-demographic data. After that, they were asked to tell if they were satisfied with their profession, what goals of their own as a coach they set to educate athletes, and what kind of goals athletes set for themselves. Further coaches were asked about moral education in sport, honourable behaviour, a good coach.

Procedures. The second author conducted individual interviews with each coach lasting between 20 and 70 minutes. The interview was designed to facilitate participants' ability to discuss their perspectives about moral education in sports. At the beginning of the interview participants were reminded of the study purposes and were asked for permission to record the interviews.

Data analyses. The interview data were analysed using the methodology of thematic analysis, which is a widely-used qualitative data analysis method. The purpose of thematic analysis is to identify patterns of meaning across a dataset that provide an answer to the research question being addressed (Braun \& Clarke, 2006). Thematic analysis was also chosen because it is particularly appropriate when research questions relate to people's opinions, attitudes about something or personal experiences. The thematic analysis includes the steps that were followed in analysing the data of this study. Firstly, researchers were familiarized with the transcribed data, which were read several times, and the preliminary ideas were marked. Subsequently, meaningful units were coded. Attempts were made to highlight as many code as possible. Later we searched for links between individual codes, non-linking codes are grouped into themes. At this stage, the first and the second authors analysed the data separately. After that, the themes were reviewed, some were merged, evaluated how they fitted with all data. Subsequently, the codes constituting the distinguished themes and sub-themes were reviewed giving labels to them. At this stage, the study was joined by the third author, who reviewed the emerging themes and sub-themes and evaluated how much they revealed a certain story related to the coaches' opinions on moral education in sports activities. In the last stage, the research data were described. In describing them, the most specific informants' citations depicting certain themes and sub-themes were selected.

Trustworthiness. In order to ensure the quality of the data, the study included coaches with different work experience, which allowed a wider range of opinions on how moral behaviour could be developed in sports activities. The audio-recorded conversations made it possible to analyse the exact statements of the informants. On the other hand, in case of uncertainty, the data obtained during the interviews were revised for the second time. Verification of data by the research participants was used, i.e. in case of doubt, the text was presented to the interview participants for consultation if they agreed with it. For data transferability and repeatability, we aimed at describing the process of data collection, processing and analysis in detail (Creswell, 2009).

\section{RESULTS}

The analysis of research results while examining the coaches' opinions on moral education in sports activities revealed the themes and sub-themes 
about the goals set in sport activities, the concept of moral education and fair play, dishonest behaviour in sports activities, moral education measures and their impact on learners, as well as the qualities of a good coach.

The goals pursued by coaches in the process of education and the goals of athletes in sports activities. According to the informants' responses reflecting their opinions on the goals in the education process, four themes were identified covering such goals pursued by educating athletes as the development of athletes' personality, motivation, the development of sports mastery and the encouragement to achieve victory (Table 1).

The interview data showed that the coaches in setting their goals related to the development of the personality of the students seek to develop their social skills and moral values. Among social skills, communication, teamwork, self-confidence and trust in team members were particularly emphasized. This is especially important in team sport aiming at achieving sports results and becoming more resistant to failures: “...while communicating they are learning to work in a team; on the other hand, communication helps them make friends, when communicating they improve their image, feel significant and at the same time realize their personal aspirations". The coaches mentioned that it was important to develop moral values such as responsibility and respect: "in sport it is also very important to be polite, tolerant, and resolve disputes without violence and aggression $<\ldots>$. It is important to feel responsibility for yourself, your actions, discipline". It is also important to convey the knowledge and skills as well as their experience to the learners, thus enhancing their motivation for sports: "I am trying to get children interested in basketball as much as I am interested in it as well as the bigger part of Lithuania so that they will love basketball as I love basketball". Two informants noted that it is important to develop athletes' life skills: "they need to be taught from an early age so that they could adapt to the modern world".

Among the goals mentioned above, there were the desire to develop sport skills in teaching sports techniques and tactics and the ability to make the necessary decisions in the match. As one informant pointed out, "it's important for them to convey all the subtleties of sport when working with children". The coaches also mentioned the importance of psychological training for athletes. According to one informant: "the coach's duty is to teach

\begin{tabular}{|c|c|c|c|}
\hline \multicolumn{2}{|r|}{ Coaches' goals } & \multirow[b]{3}{*}{ 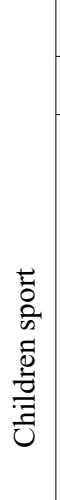 } & \multirow{2}{*}{$\begin{array}{c}\text { Coaches' approach to athletes' goals } \\
\text { Subtheme }\end{array}$} \\
\hline Theme & Subtheme & & \\
\hline $\begin{array}{l}\text { Personality } \\
\text { education }\end{array}$ & 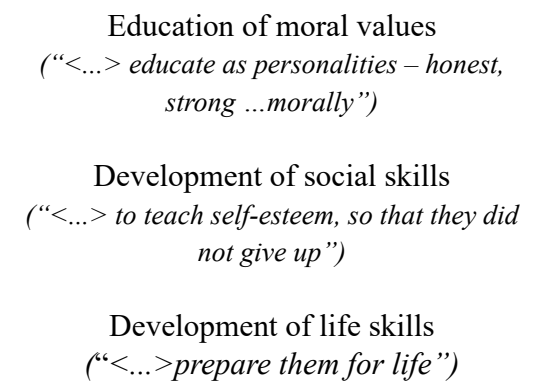 & & 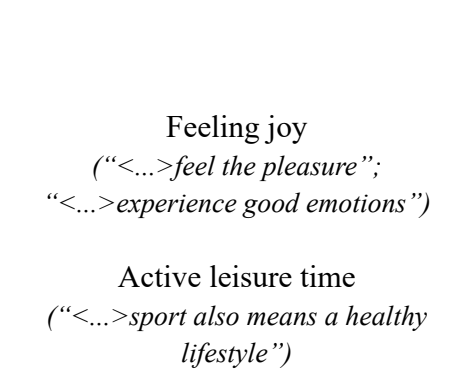 \\
\hline Motivation & 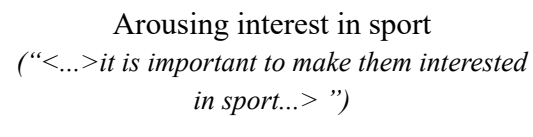 & & $\begin{array}{c}\text { Competition } \\
\text { ("Achieve the highest possible athletic } \\
\text { performance". ,, }<\ldots>\text { want to be }\end{array}$ \\
\hline $\begin{array}{l}\text { Education of } \\
\text { excellence }\end{array}$ & $\begin{array}{c}\text { Development of mental skills } \\
\text { ("Most important is }<\ldots>\text { teach them } \\
\text { teamwork, teach how to manage emotions, } \\
\text { trust teammates and themselves") } \\
\text { Development of competitive skills } \\
\text { (" }<\ldots>\text { to teach sports subtleties, techniques, } \\
\text { tactics") }\end{array}$ & 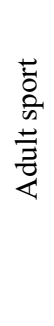 & $\begin{array}{c}\text { champions") } \\
\text { Material well-being } \\
(\text { “<..>there is no longer such an } \\
\text { aspiration as high goals". " }<\ldots>\text { athletes } \\
\text { become consumer personalities") } \\
\text { Achievements and career } \\
\text { ("To achieve the highest possible sports }\end{array}$ \\
\hline $\begin{array}{l}\text { The pursuit of } \\
\text { victory }\end{array}$ & $\begin{array}{l}\text { The top pursuit } \\
(\text { "“<..> squeeze out the maximum from } \\
\text { themselves and the team to win every match") }\end{array}$ & & 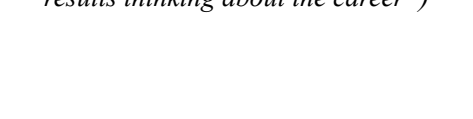 \\
\hline
\end{tabular}

Table 1. Coaches' approach to their goals and the goals of athletes in their sports activities 
athletes not to give up while training or during the tournament". Besides, the latter objectives relate to the goal of achieving the highest sports results. It is worth mentioning that the goals related to personal development and motivation were more emphasized by the coaching staff for younger children, and the development of excellence and maximizing the results, seeking victories - coaches working with older and adult athletes.

The goals of the athletes mentioned by the coaches are partly in line with their own expectations (Table 1). According to the coaches, athletes seek goals related to both internal and external motivation. Sport for children is active leisure and occupation, social self-realization, experience of positive emotions or joy: "For kids, sport is primarily a game, have fun, spending time in a "cool" way". All informants draw attention to the importance of children's social recognition as a goal of participation in sport: "They aim show off, make as many shots as possible or just want to be part of a team" We observed that coaches who trained older children emphasized the athletes' desire to win. The study also revealed another important goal for athletes - seeking career and material well-being. As one coach said: "As a coach with many years of experience, I can say that today's athletes are practicing sports without an idea or purpose, but in order to gain more financial advantage. There is no longer such an aspiration as high level goals".

The concept of moral education. The study revealed how coaches perceived moral education in sport (Table 2). Coaches defined moral education through such moral values as the development of the authority of an athlete, respect for fair play, compliance with rules, and integrity. At the same time, it was observed that they were trying to shift responsibility of moral education to parents, indicating that the family played the leading role in the formation and development of moral values in young athletes ("The most important values, including moral ones, athletes bring from the family", "in education, the coach plays a very important role but after the family") as well as the school ("First of all, children are morally educated at school, where they get the basics"), but only then the sports coach. Thus, athletes already bring certain values from the immediate environment - parents, teachers and friends, which are deeprooted in sports activities, or athletes develop new values, i.e. sport provides opportunities for wider expressions of moral values. As coaches link moral education with value education, the study allowed their perspectives to be interpreted about what specific values are important in training athletes (Table 2). The table shows that respect, honesty, and justice were mentioned. However, the coaches also reveal the reasons why it is important to nurture these values in particular. For example, development of respect for each other makes it possible to achieve team awareness: "the team is like a fist, all its members are equal". This is related to the pursuit of team spirit and, at the same time, to the promotion of affection to the sport itself. On the other hand, the values and attention to be developed must be constantly considered. As one coach posted, values must be "inventoried", reviewed: "here we could compare the athlete with the flower. If the flower is honestly watered every day, it grows green and nurtures. If the players take care of themselves, "water themselves", they will improve". In addition, existing differences between generations can be challenging when developing certain values in sports activities: " $a$ modern athlete comes with altered moral values. For example, respect for an adult is already understood differently".

The concept of Fair Play. In defining moral education, coaches often mention respect, honourable behaviour, fair play. Therefore, the data revealed how the coaches understood fair play. In addition, during their interviews, their attitudes towards dishonest behaviour were also highlighted (Table 3). Coaches linked fair play with honesty, justice and respect for others and sport. Thus, fair play was associated with a friendly contest. The concept of respect for others and the sport itself was not perceived as a specific slogan among coaches. Their statements revealed deeper meanings: "For example, at the end of the match, the team has a 100-point lead - so longer kick the ball, put it on the ground and shake opponent's hand. Show dignity", "If the opponent defeated me, on that day I have to show him special attention and respect because he won. I bow to him and thank him". No coincidence that when the coaches were asked if fair play in modern sport was important, everyone said that it was very important.

Unfair behaviour in sports activities. Coaches observe the manifestations of unfair behaviour and evaluate it negatively: "evil, 
Table 2. The concept of moral education in coaches' perspectives

\begin{tabular}{|c|c|c|}
\hline The concept of moral education & & Moral values important in athlete education \\
\hline Sub-theme & & Sub-theme \\
\hline 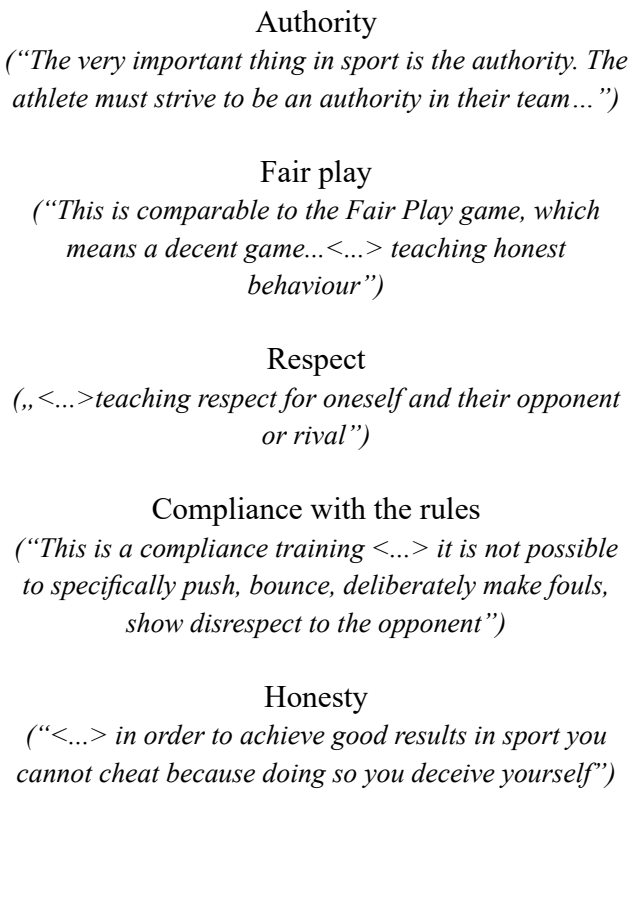 & $\begin{array}{l}\text { Moral } \\
\text { values }\end{array}$ & 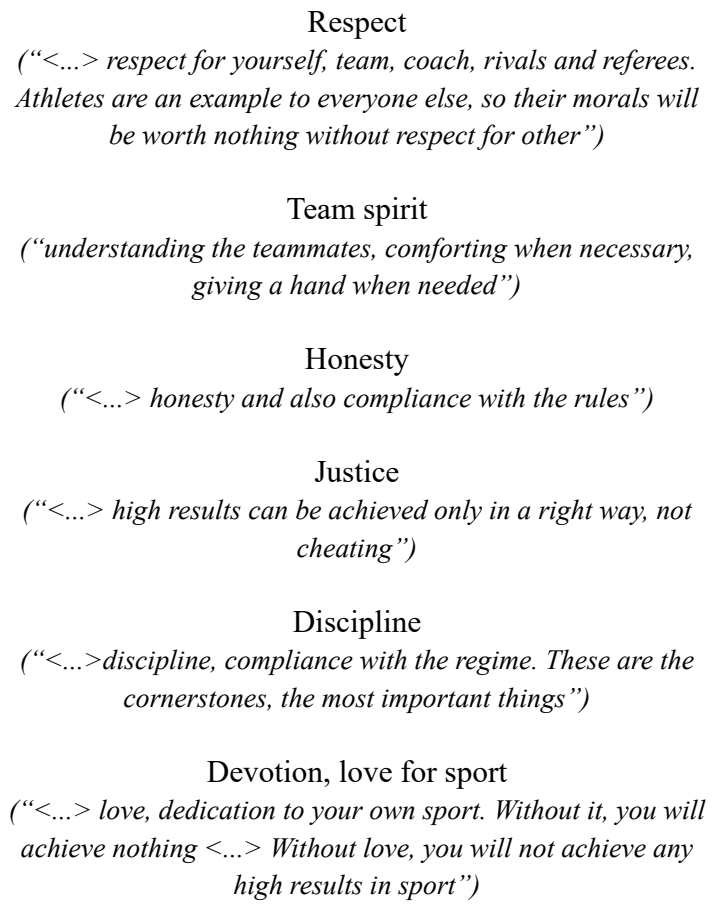 \\
\hline
\end{tabular}

Table 3. Coaches' perspectives about fair play and unfair behaviour

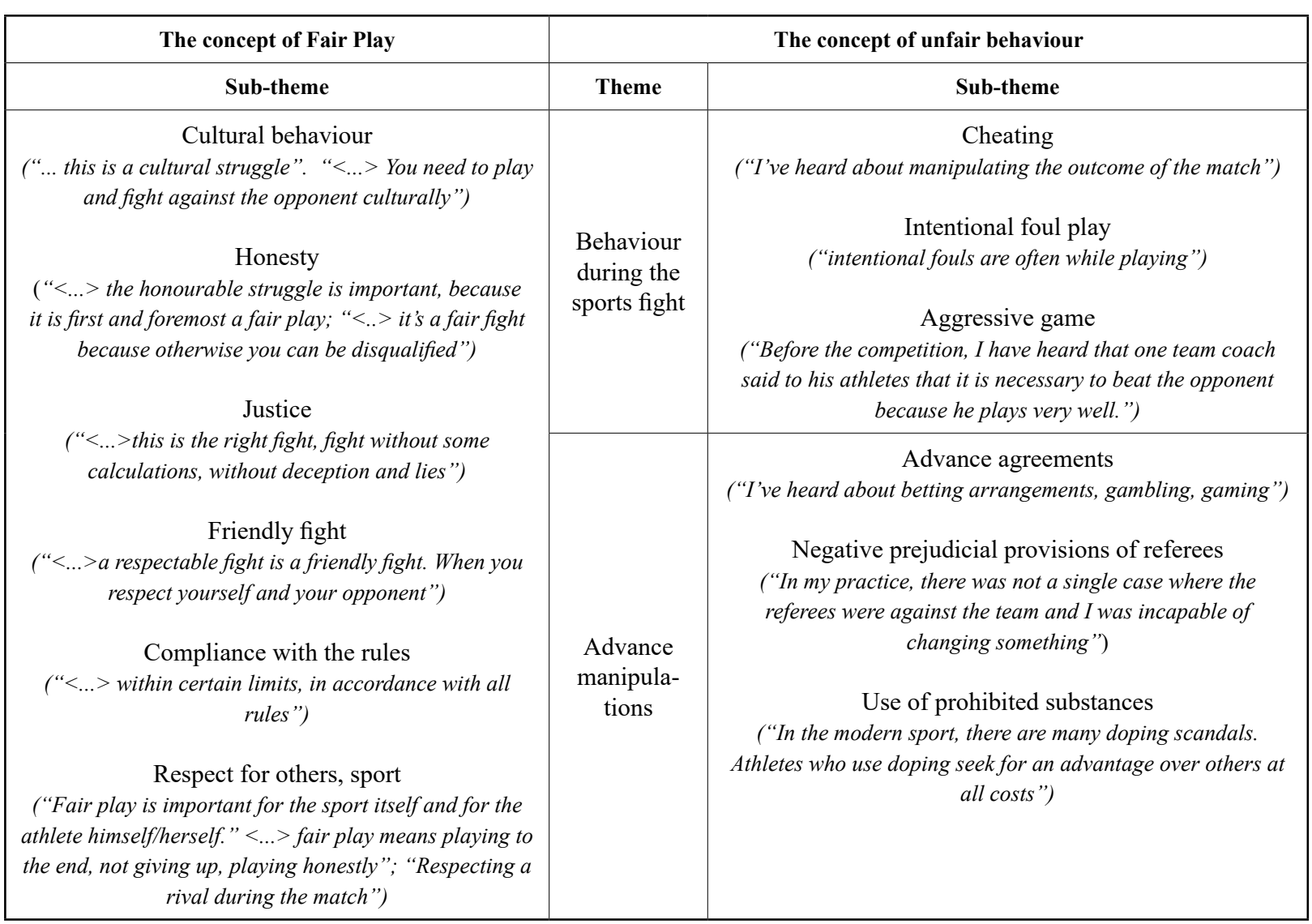


Table 4. Coach's opinions on the means of moral education and their impact

\begin{tabular}{|c|c|}
\hline Means of moral education & Impact of moral education \\
\hline 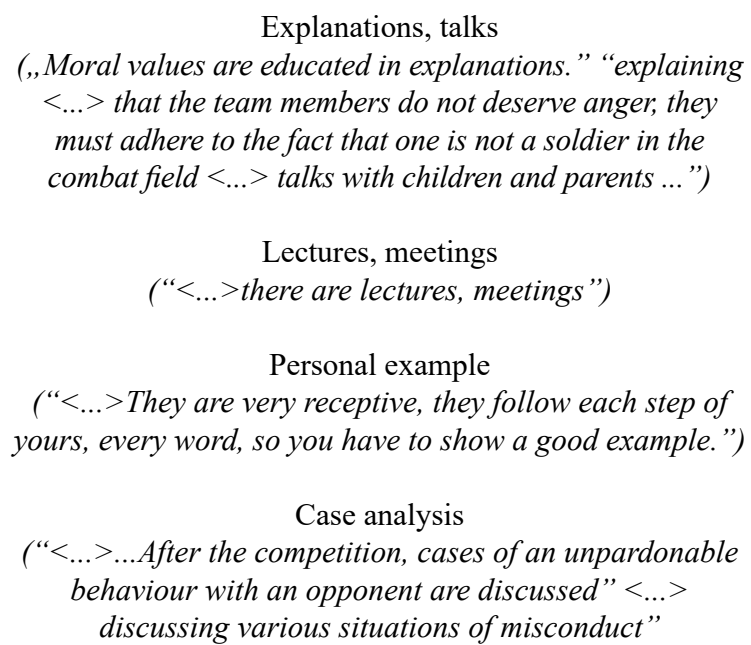 & 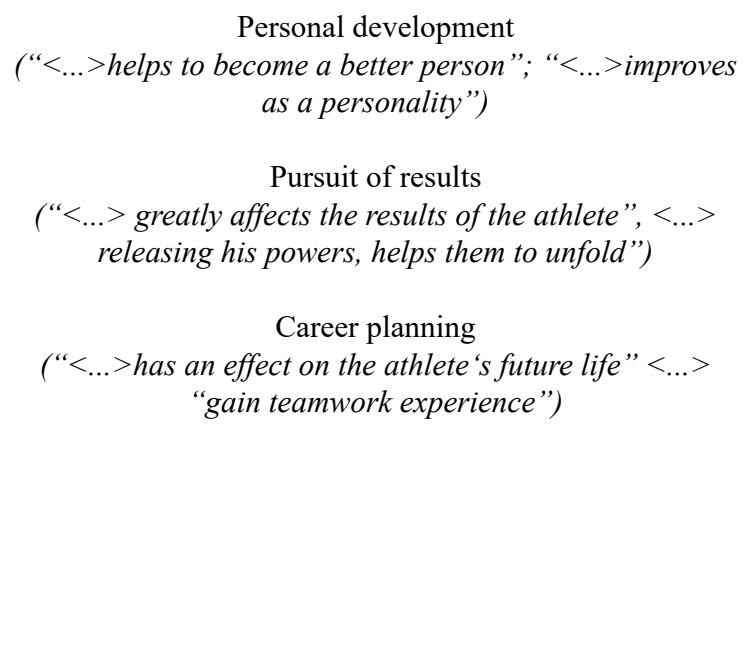 \\
\hline
\end{tabular}

immoral and shameful". The unfair behaviour mentioned by coaches can be linked to behaviour in matches and advance manipulations (Table 3). The first group includes fraud and aggressive behaviour, while the second group includes doping and advance agreements. It should be noted that athletes behave in this way not only encouraged by coaches ("I've heard when a team coach was telling his athletes before the competition ... only when we are aggressive we can win") but also without their encouragement ("they want to be cannier than each other"). Doping was seen as a particularly dishonest behaviour, as illustrated by the words of one coach: "In the modern sport, there are lots doping scandals. Athletes who use doping seek advantage over others at any cost. This is very bad because sport is no longer a real charm. Doping simply violates the principle of fair competition." On the other hand, fraudulent actions used by athletes during a match are not regarded as cheating or unfair struggle. However, the question "Do you discuss unfair competition, judging, and doping scandals during training sessions?", was responded negatively by some of the coaches.

Means of moral education and their impact on learners. The analysis of measures used for moral education showed that coaches usually used explanations and talks with athletes during training sessions or in the informal environment (Table 4). They discussed cases of unfair behaviour both in competitions and training sessions. As one coach said: "It is important and useful to discuss their own unfair competition situations or those seen by other athletes on the court in order to avoid this in the future". The importance of personal examples for athletes was also highlighted in the speeches of coaches working with both younger and older athletes: "the coach cannot relax $<\ldots>$ and this is especially important in the training of the youngest athletes who are prone to anything that simulates adult behaviour", the coach's communication culture, dedication to sport, his/her attitude to negative events in sport, etc. affects the morale of the athletes themselves". However, there are also challenges when a personal example does not easily produce results, because, as revealed in the statements of informants: modern athlete comes with alternated moral values. For example, respect for an adult is already understood differently". In addition, during the interview it turned out that two coaches were absolutely unable to say anything about the means of moral education used.

According to coaches, the moral education tools they used affected not only athletes' personal development, but also contributed to their achievements in sports results (Table 4). The developed skills of cooperation and teamwork will affect their trainees in their further careers.

Qualities of a good coach. The study revealed that good coaches should feature a series of qualities. First of all, they must be professional: " $<\ldots>$ the one who has much knowledge and is able to convey it correctly and purposefully, i.e. which conveys knowledge methodically" <...> must know what they are doing". Also, the coach must be an authority: "<... you need to be an example. Then your trainees will appreciate and respect you" $<\ldots>$ able to motivate them", be 
insightful as it allows you to discover future sports talents. A good coach should be able to create a good psychological climate in a team, be able to manage their emotions well: " $<\ldots>$ who is able to communicate with trainees $<\ldots>$ able to maintain a real good relationship" $<$... $>$ the coach must control their emotions". The study showed that informants payed attention to the coach's honesty, emphasizing that not only achievements in sport wee important. As one informant noted, "it is very important to be honest with yourself and your trainees". Thus, describing the characteristics of a good coach, along with the subject competences, they also emphasize moral competences.

\section{DISCUSSION}

The purpose of this study was to reveal the opinions of coaches about moral education of athletes in sports activities. Interview data revealed a more diverse view of coaches about the concept of athletes' moral education in the context of their goals in sports activities, evaluations of fair and unfair behaviours in sport as well as moral education tools applied by coaches, their opinions about the impact of these tools on developing young athletes, and the qualities of a good coach.

The study revealed that the objectives of coaches included the development of moral values as well as social skills and sport competences. This partly echoes previous research, which grounded the effect of the development of social skills in sports activities on the personal development of athletes (Milavič, Grgantov, \& Milič, 2013). The goal of coaches to motivate athletes is of no surprise because it is important not only to encourage children and young people to take part in the activity, but also to achieve sports results. This explains the purpose of coaches to develop sports excellence. Besides, the possibilities for a coach to affect athletes' motivation and intentions to make certain behavioural decisions are great, as confirmed by previous research (Curran, Hill, Hall, \& Jowet, 2015; Kavusannu, Boardley, Jutkiewicz, Vincent, \& Ring, 2008). Thus, the goals of coaches are diverse, including the ambition to train athletes as personalities, as well as their sports excellence, while also contemplating their achievements.

Coherence between coaches and athletes' expectations is essential for success in sport, as was partly revealed by the study. According to coaches, athletes seek both positive emotions and active leisure time. The coaches also think that sport provides the opportunity for athletes to compete and achieve victory. Such goals in sport are also raised by the coaches themselves. These results confirm previous data that participation in sports activities involves various forms of emotional expression, including the experiences of joy and pleasure (Koh, Wang, \& Chew, 2014; MacDonald, Côte, Eys, \& Deakin, 2011). On the other hand, while giving children the joy of small achievements, in the long run sport becomes a motivating factor for them, an interesting and meaningful activity, later transforming into a way of life (McMillan, McIsaac, \& Janssen, 2016; Perrotta \& Pannelli, 2014; Prichard \& Deutsch, 2015). However, the goals set for the development of a personality, the realization of the desire for experience of joy and the pursuit of winning can raise many challenges for coaches when choosing priorities. Other research on coaching shows that due to the demands of competition, coaches sometimes found it difficult to balance the teaching of values with the need to win (Romand \& Pantaleon, 2007).

Sport based on moral values has a special educational effect on the personality as it broadens the field of a person's culture, excites positive emotions to make moral decisions, and give meaning to positive behaviour in a particular situation (Budreikaite, 2013). According to the research findings, coaches also define moral education through perception of moral values - respect, authority, honourable behaviour, compliance with rules and honesty. Similarly, the coaches refer to these values when talking about the values that are important in the development of athletes. In other studies explaining how coaches perceive morality and moral character, they emphasized the values they were trying to teach their athletes (Pelaez, Aulls, \& Bacon, 2016; Rudd \& Mondello, 2006). It should be noted that these values are divided into moral values (doing what is right on behalf of the others' wellbeing) and social values (hard work, caring about others) (Rudd \& Mondello, 2006). Our research results extend the previous ones as the coaches' statements on moral education include love, commitment to sport and discipline. Devotion and discipline should be attributed to more instrumental values that are important for the athletic outcomes. We should similarly evaluate love to sport mentioned by the coaches which is explained by a certain dedication as the key to achieving success in sport.

Coaches also relate moral education to fair behaviour, which they also identify with honesty, 
justice, friendliness, and compliance with rules. Analysing these data, we may raise the question of how much such evaluations of fair play are declarative and not actually associated with the cultivating of these values or moral behaviour. As previous studies showed, that it is much harder for coaches to characterize their own moral behaviour than that of others (Pelaez, Aulls, \& Bacon, 2016), which can be an explanation that coaches either do not agree with the values they have to transmit or that they perceive that athletes' moral development is not their responsibility. This position has been described as 'partisanship' (Simon, Torres, \& Hager, 2014). It should be noted that some research participants also stated that they did not analyse examples of abusive behaviour with their trainees. However, at the same time they advocate negatively about the disgraceful behaviour in sport, which embraces aggressive behaviour and intentional fouls, and various manipulations of the game outcomes. They also have very negative attitudes about doping in sport. This is a reflection of previous coaches' surveys with the most negative assessments of forms of cheating that involve various prior agreements (Šukys \& Nickus, 2009). However, in our research about dishonest behaviour, the coaches often referred to others, and that did not reflect their own personal behaviours.

The study also sought to identify ways in which moral values were conveyed. The results revealed that the most suitable method for conveying moral values to trainees was talks with athletes, especially if this happened in an informal environment. In addition, personal example of a coach is also important, which confirms the coach's role not only in motivating athletes (Keegan, Harwood, Spray, \& Lavallee, 2014) but also creating the team's moral atmosphere (Shields, LaVoi, Bredemeier, \& Power, 2007). Previous studies also confirm the importance of the coach's personal example, as he/she is an influential person in the athlete's life because the coach is regarded as an expert in their field, which can have a significant influence on their decisions and behaviour (Kavusannu et al., 2008). The coach's mastery enables the athletes to trust them, to respect them, to learn from a constantly observable example (Boardley \& Jackson, 2012; Delgado \& Gomez, 2011). Meanwhile, creating a conflict environment when unsuccessful athletes are laughed at and condemned for failures predicts poor sport behaviours of athletes (Davies, Stellino, Nichols, \& Coleman, 2015). Besides, according to coaches who participated in the research, the moral education measures affect the development of the personality of the trainees and help them to achieve sports results and pursue further career. We suggest that the measures of moral education applied at the same time help create motivational climate of excellence, which affects athlete's confidence, dedication, enthusiasm and vigour in sports activities (Curran et al., 2015), and which is also related to sports results.

The work of a coach is responsible, complex and challenging (Lisinskienè, 2016), so a good coach must have certain characteristics. The finding of our research also showed that research participants attributed the ability to encourage moral behaviour as an important quality of a good coach. Coaches also recognized the ability to create a good microclimate in the team, to be in authority, and to be a professional in their field. Thus the informants mentioned the qualities of a good coach which partly reiterated their opinions about what was important in developing moral behaviour and achieving goals in sports activities. It also reflects the coach's ability to develop athlete's skills, motivate, build character, mentioned in the coaching efficiency model (Boardley, 2017). Besides, the ability to build good team relationships is important not only working with children. This is also important in professional sport as previous research with Olympic medallists showed that athlete-coach relationship has an important role to play in the athlete's development both as a performer and as a person (Jowett \& MCockerill, 2003). On the other hand, as other studies show, coaches rate themselves according to coaching efficacy higher than their athletes (Kavussanu et al., 2008).

Coaches' perspectives on moral education in sports activities also revealed the emerging challenges in developing children athletes. The system of values and behavioural models for children are primarily affected by the family (Hardy, PadillaWalker, \& Carlo, 2008), as well as school and peers (Barni, Ranieri, Scabini, \& Rosnati, 2014). Therefore, a coach who works with children can face a great challenge, especially if his/her system of values in sports is different from that of trainees. On the other hand, when it comes to working with adolescents, it is important that at this age they tend to seek new meanings in values, and this puts a special responsibility on the coach. It is worth mentioning the role of 
parental involvement in children's sports activities, which can also challenge the coaches. i.e. parents can influence both positive and negative (Holt \& Knight, 2014; Knight, Berrow, \& Harwood, 2017). Therefore, in the education of moral behaviour in athletes, the coach also has to have the ability to cooperate with the parents.

Although our findings extend the understanding of moral education in sport, this research possesses limitations that must be acknowledged together with future research perspectives. The study involved only one female coach. Therefore, in further studies, it would be relevant to further analyse the views of female coaches on moral education in sport as well as its progress. It should be mentioned that the study involved only football and basketball coaches. We believe that in further research it is relevant to analyse the opinions of coaches in other sports. The obtained findings further raised the question of whether coaches tended to observe only the dishonest behaviour of others in sports and how their negative attitudes were in line with their personal decisions and behaviour in sport.

\section{CONCLUSION}

This qualitative study presents the perspectives/ views of coaches regarding the youth moral education in sport. The findings suggest that coaches define moral education in sport through the education of moral values. It has been determined that the goals set by coaches are also related not only to the sports results, but also to the development of the personality of athletes. According to coaches, in the education of moral behaviour of athletes, the personal role of the coach is of great importance, i.e. the coach's authority, professionalism, insight, self-control, honesty, and the ability to create a favourable team psychological climate, which at the same time helps to develop both the athlete's personality and the athletic performance.

\section{REFERENCES}

Al-Yaaribi, A., Kavussanu, M., \& Ring, C. (2016). Consequences of prosocial and antisocial behavior for the recipient. Psychology of Sport and Exercise, 26, 102-112. doi: 10.1016/j.psychsport.2016.06.012

Bergmann-Drewe, S. (1999). Moral reasoning in sport. Sport, Education and Society, 4, 117-130.

Boardley, I. D. (2017). Coaching efficacy research: Learning from the past and looking to the future. International Review of Sport and Exercise Psychology, Advance online publication. http://dx.doi.org/10.1080/1 750984X.2017.1290816

Boardley, I. D., \& Jackson, B. (2012). When teammates are viewed as rivals: A cross-national investigation of achievement goals and intrateam moral behavior. Journal of Sport \& Exercise Psychology, 34, 503-524.

Boardley, I. D., \& Kavussanu, M. (2009). The influence of social variables and moral disengagement on prosocial and antisocial behaviours in field hockey and netball. Journal of Sports Sciences, 27, 843-854. http://dx.doi. org/10.1080/02640410902887283

Bortoli, L., Messina, G., Zorba, M., \& Robazza, C. (2012). Contextual and individual influences on antisocial behaviour and psychobiosocial states of youth soccer players. Psychology of Sport and Exercise, 13, 397-406. https://doi.org/10.1016/j.psychsport.2012.01.001

Braun, V., \& Clarke, V. (2006). Using thematic analysis in psychology. Qualitative Research in Psychology, 3, 77-101. doi: 10.1191/1478088706qp063oa

Bruner, M. W., Boardley, I. D., Allan, V., Root, Z., Buckham, S., Forrest, C., \& Côté, J. (2016). Examining social identity and intrateam moral behaviors in competitive youth ice hockey using stimulated recall. Journal of Sport Sciences. Advance online publication. http://dx.doi.org/10.1080/ 02640414.2016.1243797

Budreikaitè, A. (2013). Olimpinio ugdymo ịtaka paauglių dorovinių vertybių raiškai. Tiltai, 1, 121-133.

Creswell, J. W. (2009). Research design: Qualitative, quantitative, and mixed methods approaches. Sage Publications, Inc.

Curran, T., Hill, A. P., Hall, H. K., \& Jowet, G. E. (2015). Relationships between the coach-created motivational climate and athlete engagement in youth sport. Journal of Sport \& Exercise Psychology, 37, 193-198.

Davies, M. J., Stellino, M. B., Nichols, B., \& Coleman, L. M. (2015). Otherinitiated motivational climate and youth hockey players' good and poor sport behaviours. Journal of Applied Sport Psychology, 28(1), 7896. http://dx.doi.org/10.1080/10413200.2015.1071297

Hardman, A., Jones, C., \& Jones, R. (2010). Sports coaching, virtue ethics and emulation. Physical Education and Sport Pedagogy, 15, 345-359. doi: 10.1080/17408980903535784

Hodge, K., \& Lonsdale, Ch. (2011). Prosocial and antisocial behavior in sport: The role of coaching style, autonomous vs. controlled motivation, and moral disengagement. Journal of Sport \& Exercise Psychology, $33,527-547$.

Holt, N. L., \& Knight, C. J. (2014). Parenting in youth sport. New York: Routledge.

Holt, N. L., Neely, K. C., Slater, L. G., Camiré, M., Côté, J., Fraser-Thomas, J., ... Tamminen, K. A. (2017). A grounded theory of positive youth development 
through sport based on results from a qualitative metastudy. International Review of Sport and Exercise Psychology, 10(1), 1-49. http://doi.org/10.1080/175098 4X.2016.1180704

Jowett, S., \& MCockerill, I. M. (2003). Olympic medallists' perspective of the athletecoach relationship. Psychology of Sport and Exercise, 4(4), 313-331.

Kavusannu, M., Boardley, I. D., Jutkiewicz, N., Vincent, S., \& Ring, C. (2008). Coaching efficacy and coaching effectiveness: Examining their predictors and comparing coaches' and athletes' reports. The Sport Psychologist, 22(4), 383-404.

Keegan, R. J., Harwood, Ch. G., Spray, Ch. M., \& Lavallee, D. (2014). A qualitative investigation of the motivational climate in elite sport. Psychology of Sport and Exercise, 15, 97-107.

Knight, C. J. Berrow, S. R., \& Harwood, Ch. G. (2017). Parenting in sport. Current Opinion in Psychology, 16, 93-97.

Koh, K. T., Wang, C. K. J., \& Chew, W. C. E. (2014). Participation in physical activity and sports in Singapore: Barriers and enablers. International Sports Studies, 36(2), 5-18.

Lisinskienè, A. (2016). Tèvu ir paaugliu ugdomoji squeika sportineje veikloje: daktaro disertacija. Lietuvos sporto universitetas.

MacDonald, D. J., Côte, J., Eys, M., \& Deakin, J. (2011). The role of enjoyment and motivational climate in relation to the personal development of team sport athletes. The Sport Psychologist, 25, 32-46.

McMillan, R., McIsaac, M., \& Janssen, I. (2016). Family structure as a correlate of organized sport participation among youth. PLOS ONE, 11(2), 1-12. doi: 10.7717/ peerj. 1048

Milavič, B., Grgantov, Z., \& Milič, M. (2013). Relations between coping skills and situational efficacy in young female volleyball players. Physical Education and Sport, 11(2), 165-175.

Moreno, J. A., \& Cervello, E. (2005). Physical selfperception in Spanish adolescents: Effects of gender and involvement in physical activity. Journal of Human Movement Studies, 48, 291-311.

Ntoumanis, N., Taylor, I. M., \& Thøgersen-Ntoumani, C. (2012). A longitudinal examination of coach and peer motivational climates in youth sport: Implications for moral attitudes, well-being, and behavioral investment. Developmental Psychology, 48, 213-223.
Pelaez, S., Aulls, M. W., \& Bacon, S. L. (2016). Morality in sport: The coach's perspective. International Journal of Sport Science \& Coaching, 11(2), 237-249. doi:10.1177/1747954116637494

Perrotta, F., \& Pannelli, A. (2014). Sport for the formation of the person: "Sport as an educational tool, training of adults and children: A resource for school and strategy for the job". Acta Kinesiologica, 8(2), 25-28.

Popescu, V. (2012). Role of sport activities in the formation of ethical moral values. Sport şi Societate, 12(2), 184-189.

Prichard, A., \& Deutsch, J. (2015). The effects of motivational climate on youth sport participants. Physical Educator, 72, 200-215.

Romand, P., \& Pantale'on, N. (2007). A qualitative study of rugby coaches' opinions about the display of moral character. The Sport Psychologist, 21, 58-77.

Rudd, A. K., \& Mondello, M. J. (2006). How do college coaches define character? A qualitative study with division IA head coaches. Journal of College and Character, 7(3), 1-10.

Rutten, E. A., Dekovic, M., Stams, G. J. J. M., Schuengel, C., Hoeksmad, J. B., \& Biesta, G. J. J. (2008). On- and off-field antisocial and prosocial behavior in adolescent soccer players: A multilevel study. Journal of Youth and Adolescence, 31, 371-387.

Shields, D. L., LaVoi, N. M., Bredemeier, B. L., \& Power, C. (2007). Predictors of poor sportspersonship in youth sports: Personal attitudes and social influences. Journal of Sport \& Exercise Psychology, 29, 747-762.

Simon, R. L, Torres, C. R., \& Hager, P. F. (2014). Fair play: The ethics of sport. New York: Westview Press.

Sparkes, A. C., \& Smith, B. (2014). Qualitative research methods in sport, exercise and health. From process to product. New York: Routledge.

Sukys, S., \& Nickus, E. (2009). Coaches' attitudes towards deception in sports activities. Sport Science, 1(59), 28-35.

Traclet, A., Romand, Ph., Moret, O., \& Kavussanu, M. (2011). Antisocial behaviour in soccer: A qualitative study of moral disengagement. International Journal of Sport and Exercise Psychology, 9(2), 143-155.

Winstein, N., \& Ryan, R. M. (2010). When helping helps: Autonomous motivation for prosocial behavior ant its influence on well-being for the helper and the recipient. Journal of Personality and Social Psychology, 98, 222-244. 